\title{
Education and information needs for physicians about rare diseases in Spain
}

\author{
Enrique Ramalle-Gómara', Elena Domínguez-Garrido ${ }^{2 *}$ D, María Gómez-Eguílaz ${ }^{3}$, María Eugenia Marzo-Sola ${ }^{3}$, \\ José Luis Ramón-Trapero ${ }^{4}$ and Josefa Gil-de-Gómez ${ }^{5}$
}

\begin{abstract}
Background: Rare diseases are a priority objective for public health systems. Given its complexity, late and misdiagnoses occur very often which causes mental and physical burden for patients and family. This would be caused, in part, for unprepared clinicians in this field. The aim of this study was to report the training needs and the perceived shortcomings of Spanish physicians of the public health system in the diagnosis, treatment and monitoring of patients with rare diseases.

Methods: We used a descriptive cross-sectional study through an "ad hoc" survey of 26 questions was completed by 132 primary care physicians and 37 specialists during April and May 2018.

Results: Less than a third of the physicians had received training in rare disease during their undergraduate or postgraduate years, and for hospital professionals, they received more training in the postgraduate period.

Conclusion: Primary care physicians and specialists showed low training level in rare diseases. An academical and continuous program on rare disease, as well as, multidisciplinary units and high quality practice guidelines are necessary to help to prevention and support clinical decisions and improve quality of care of patients and families.
\end{abstract}

Keywords: Rare diseases, Education and information needs, Clinicians, Survey

\section{Background}

According to the European Union (EU), a disease is considered rare when it affects no more than one person in 2000. Rare diseases (RDs) are serious, chronic, and often life-threatening conditions [1]. It has been estimated that from 6 to $8 \%$ of the population will be affected by a rare disease [2]. This means that in EU between 27 to 36 million individuals will be affected by these diseases [3]. In the UK, it has been estimated that 1 in 17 individuals may have a rare disease throughout their lives [4]. A pilot study in Spain, covering $80 \%$ of the population, detected a total of 824,399 rare disease cases [5].

These diseases are an important challenge that affects public health, the development of new diagnostic methods and therapies, and the clinical, social and health care that these patients require. A recurrent concern of these patients and their families is the limited knowledge that physicians have about it due to the high clinical complexity,

\footnotetext{
* Correspondence: edominguez@riojasalud.es

${ }^{2}$ Rioja Health Foundation, La Rioja, Spain

Full list of author information is available at the end of the article
}

which results in late diagnosis and misdiagnosis [6]. The average time between the onset of symptoms and the diagnosis of a patient with a rare disease has been estimated to be close to 6 years, while in the pediatric age it is longer than 15 months [7]. This situation can be frustrating for both health professionals and patients.

Huete et al. [8] showed that the lack of specific training of health professionals in this field means that $78.8 \%$ of those affected patients have not received appropriate care, while $56 \%$ did not receive correct care. According to Kopeć et al. [9], healthcare workers reported that physicians and medical students have insufficient knowledge and limited training in rare diseases; even parents report that they often educate their pediatrician/physician about their child's rare disease [10].

Professionals need specialized training focused on the acquisition and maintenance of the necessary competencies for an adequate care of these patients and families, and improved communication processes with an assertive, informed, involved and interactive patient in the treatment process [11]. 
In 2009, the Council of the European Union [12] attempted to improve training in rare diseases and recommended "...sufficient education and training for all health professionals, to make them aware of the existence of these diseases and resources that are available to them ", as well as "...the development of medical training in areas related to the diagnosis and management of rare diseases, such as genetics, immunology, neurology, oncology or pediatrics ". Likewise, in Spain, in its 2014 update, the Strategy on Rare Diseases of the Spanish National Health System [13] recognizes that it is necessary to improve the training of health professionals, beginning with the identification of their training needs. No information about these needs is available for healthcare professionals in Spain. In a previous study, we found differences in rare diseases knowledge from resident doctors to health and non-health future professionals [14]. Avellaneda et al. [15] described that only $20 \%$ of physicians had carried out specific training and only $15 \%$ have a good knowledge about rare diseases.

Our objective is to report the training needs and the perceived shortcomings of Spanish physicians of the public health system in the prevention, diagnosis, treatment and monitoring of patients with rare diseases.

\section{Methods}

Descriptive cross-sectional study through self-reported surveys (Additional file 1) by La Rioja (Spain) public health system medical doctors from primary care and specialized care services (oncology, hematology, neurology, pediatrics and obstetrics and gynecology). These were selected as they have the highest rate of rare disease patients.

The sample size was calculated based on a report from Esteban et al, where they provide an average of 2.12 (SD: 0.86 ) values in a Likert scale about information needs/specific training in rare diseases. Then, from a total of 261 primary care physicians, a sample size of 177 individuals would be necessary to achieve an accuracy of 0.07 units in the estimation of a mean with a bilateral confidence interval of $95 \%$ with a finite population correction.

On the other hand, a total of 87 specialized physicians (10 hematologists, 33 obstetricians and gynecologists, 10 oncologists, 13 neurologists and 21 pediatricians) were invited to participate in the study.

A questionnaire was designed based on two previous publications [16, 17]. We selected the questions about practice setting, clinical experience with rare disease patients, difficulties encountered when looking after patients with rare diseases, education received about rare diseases and current use of information resources in clinical practice from Zurynski et al. [16], and individual assessment of training in rare diseases from Esteban et al. [17]. In total, 13 questions in Likert scale format with answers from 1 to 5 were used. Five questions evaluate the training and information received about rare diseases, next 5 questions about knowledge of the centres and units in Spain dedicated to this field and the last 3 questions about the evaluation of social resources and patients' associations knowledge. Highest possible score was 65 where a higher score indicates better knowledge about these questions.

Finally, we designed three specific questions about the kind of training on rare diseases respondents would like to receive. The questions were: 1 ) Would you like to receive training on inheritance or genetic counselling? 2) Would you like to receive training in diagnosis and treatment? 3) Would you like to receive information about websites or sources of information? The answer was a Likert scale of 1 to 5 .

The questionnaire was delivered by email and their responses were manual and anonymous.

\section{Statistical analysis}

Means and standard deviations were calculated for quantitative variables and frequencies for qualitative findings. Means were compared by t-Student test or ANOVA. Scheffé's post-hoc test was used to adjust for multiple comparisons. The differences between proportions were assessed by chi-square test for contingency tables. Fisher's test was used when appropriate.

In order to assess the independent association of each covariate on the total score of the scale, a multiple linear regression analysis was carried out. The regression coefficients show the effect of each category of the independent variable on the dependent variable (total score) in relation to the reference category, adjusted for the rest of the variables included in the model. All analyses were conducted using $\mathrm{R}$ Commander. Two-tailed test were used and $p$-values $<0.05$ were considered to be statistically significant.

\section{Results}

From 264 sending surveys, we received a complete answered questionnaire of $169(64,0 \%)$ physicians, 132 (78.1\%) from primary care and 37 (21.9\%) from a hospital setting. Ninety-nine women $(58.6 \%)$ and 70 men (39.9\%), with a mean age of 50.7 years (SD, 9.0). The mean of professional practice was 24.4 years (SD, 9.0). By medical specialty, primary care was divided by area in 59 (34.9\%) urban and $73(43.2 \%)$ rural, and from hospital department, 5 (3.0\%) were from gynecology, 6 (3.6\%) hematology, $10(5.9 \%)$ neurology, $9(5.3 \%)$ oncology, and 7 (4.1\%) pediatrics.

Less than a third of the physicians had received training in rare diseases during their undergraduate or postgraduate years, and for hospital professionals, they received more training in the postgraduate period. Less 
than $40 \%$ had attended continuing education courses in the last 5 years. Sixty-five (36.4\%) did a specific course on rare diseases in the last 5 years and 61 (83.6\%) considered the courses useful (Table 1).

The main difficulties in the care of patients with rare diseases are derived from the lack of diagnostic guidelines, delay or inability to make a definitive diagnosis and uncertainty about where to refer the patient to. One significant difficulty was the lack of available treatments $(78.4 \%$ vs. $36.4 \% ; p$-value $=0.001)$ and difficulty accessing new drugs or therapies currently available overseas, not yet licensed in Spain $(45.9 \%$ vs $15.2 \%, p$-value $=0.001)$ (Table 2).

When we evaluated questions about knowledge and management of rare diseases we found that the overall score does not reach a third of the maximum score, 28.16 for hospital professionals and 22.19 for primary care (Table 3).

Regarding medical speciality, primary care and gynecologists have lower scores than their colleagues, and pediatricians showed better abilities to care for rare diseases. (Table 4 and Fig. 1).

Multiple linear regression model on the total score of the questionnaire indicated that specialists that received training courses improved the overall score (Table 5).

Finally, all physicians showed a strong interest to receive training, especially in genetic counselling, 4.1 and 4.0 out of 5 points for primary care and hospital physicians respectively $(p=0.75)$. Regarding diagnosis and treatment, both groups scored 4.2 and with regards to the need to receive information on rare diseases websites, score was 4.4 for primary and 4.2 for specialization $(p=0.19)$.

\section{Discussion}

To develop effective continuing medical education (CME) strategies that can impact clinical practice, information should initially be gathered to assess the needs and attitudes of the target group, followed by an evaluation of these educational strategies on practice [18]. Our study has shown a low degree of training of physicians, both for primary and specialized care, in the care of patients with rare diseases. The paradox of rare diseases, although individually rare, collectively affects a significant proportion of the general population, thus reflecting the well-known concept that "little drops of water will make the mighty ocean" [19]. In Australia, approximately $8 \%$ of the population live with any one of about 10,000 known rare diseases. This is similar to the proportion of people living with diabetes or asthma [20].

Therefore, most physicians will face the diagnosis or treatment of a rare disease at some point in their professional lives. In our study, almost $90 \%$ of the clinicians had cared for these patients in their professional career. In the USA it has been estimated that $1.6 \%$ of outpatient visits by primary care physicians are to care for these patients [21].

The lack of training is also perceived by patients or their families, who become experts in their disease [11]. This is a challenge for their clinicians who are unaccustomed to their patients knowing more about an illness than they do. Listening to patients / parents always with belief in what they are saying is the key to both unlocking red flags quickly and giving patients confidence in their GP. When patients were asked what was the one thing their GP could have done to improve the diagnostic journey, "Believing me" is the number one response

Table 1 Characteristics of physicians and their practice (Based in Zurynski et al.2017)

\begin{tabular}{|c|c|c|c|}
\hline Variable & $\begin{array}{l}\text { Hospital } \\
(n=37)\end{array}$ & $\begin{array}{l}\text { Primary care } \\
(n=132)\end{array}$ & $\begin{array}{l}p- \\
\text { value }\end{array}$ \\
\hline Age (Mean, SD) & $46.1(8.5)$ & $52.0(8,8)$ & 0.001 \\
\hline Years of practice (Mean, SD) & $19.9(7.9)$ & $25.6(9.0)$ & 0.001 \\
\hline Rare diseases included in medical degree $(\mathrm{N}, \%)$ & $10(27.0)$ & $35(26.5)$ & 0.832 \\
\hline Rare diseases included in post-graduate medical education (N, \%) & $19(51.4)$ & $25(18.9)$ & 0.001 \\
\hline Continuing Medical Education in the last 5 years about rare diseases ( $\mathrm{N}, \%)$ & $17(45.9)$ & $54(40.9)$ & 0.765 \\
\hline \multicolumn{4}{|l|}{ Number of rare disease patients seen during clinical career $(\mathrm{N}, \%)$ : } \\
\hline 0 & $0(0.0)$ & $7(5.3)$ & 0.002 \\
\hline $1--4$ & $6(16.2)$ & $59(44.7)$ & \\
\hline $5-10$ & $8(21.6)$ & 26 (19.7) & \\
\hline $11--15$ & $5(13.5)$ & $8(6.0)$ & \\
\hline $16--20$ & $2(5.4)$ & $6(4.5)$ & \\
\hline$>20$ & $10(27.0)$ & $20(15.2)$ & \\
\hline$>100$ & $6(16.2)$ & $5(3.8)$ & \\
\hline
\end{tabular}

*Significant difference $p<0.05$ 
Table 2 Difficulties encountered by physicians while caring for patients with rare diseases (Based in Zurynski et al.2017)

\begin{tabular}{|c|c|c|c|}
\hline \multirow[t]{2}{*}{ Variable $(\mathrm{N}, \%)$} & \multirow{2}{*}{$\begin{array}{l}\text { Hospital } \\
(n=37)^{\mathrm{a}}\end{array}$} & \multirow{2}{*}{$\begin{array}{l}\text { Primary care } \\
(n=132)^{\mathrm{a}}\end{array}$} & \multirow[t]{2}{*}{$p$-value } \\
\hline & & & \\
\hline Lack of diagnostic guidelines & $26(70.3)$ & $78(59.1)$ & 0.211 \\
\hline Lack of access to diagnostic tests & $12(32.4)$ & $44(33.3)$ & 0.918 \\
\hline Delay or inability to make a definitive diagnosis & $23(62.2)$ & $89(67.4)$ & 0.552 \\
\hline Lack of treatment or management guidelines & $21(56.8)$ & $77(58.3)$ & 0.864 \\
\hline Lack of available treatments & $29(78.4)$ & $48(36.4)$ & 0.001 \\
\hline $\begin{array}{l}\text { Difficulty accessing new drugs or therapies currently available } \\
\text { overseas, not yet licensed in Spain }\end{array}$ & $17(45.9)$ & $20(15.2)$ & 0.001 \\
\hline Uncertainty about where to refer patients to & $23(62.2)$ & $88(66.7)$ & 0.612 \\
\hline $\begin{array}{l}\text { Difficulties in accessing allied health services (Physiotherapy, } \\
\text { psychology,...) }\end{array}$ & $9(24.3)$ & $41(31.1)$ & 0.421 \\
\hline Difficulties in accessing genetic testing & $12(32.4)$ & $42(31.8)$ & 0.944 \\
\hline $\begin{array}{l}\text { Uncertainty about available peer support groups for the patient } \\
\text { and family }\end{array}$ & $14(37.8)$ & $59(44.4)$ & 0.476 \\
\hline
\end{tabular}

${ }^{\mathrm{a}}$ Significant difference $p<0.05$

[22]. The existence of clinical practice guidelines can improve clinical decision making and public health [23]. Few years ago, some specialized webs offer this content in Spanish, as an example, Enfermedades Raras-Orphanet (https://www.orpha.net).
Doctors are not aware of socio-health resources or referral centres available for these patients. The scores on the scale do not reach 3 points, as Esteban et al. pointed out [17]. Therefore, the difficulties in making an adequate diagnosis, prescribing treatment or guiding patients about

Table 3 Likert questions about training for the management and knowledge of rare diseases.(Based in Esteban Bueno et al. 2015)

\begin{tabular}{|c|c|c|c|}
\hline Questions & $\begin{array}{l}\text { Hospital } \\
(n=37) \\
\text { Mean (SD) }\end{array}$ & $\begin{array}{l}\text { Primary care } \\
(n=132) \\
\text { Mean (SD) }\end{array}$ & $p$-value \\
\hline $\begin{array}{l}\text { I consider that the medical training (clinical aspects) that I have received } \\
\text { on rare diseases is adequate }\end{array}$ & $2.29(0.94)$ & $1.72(0.96)$ & 0.001 \\
\hline $\begin{array}{l}\text { I believe that the training I have received on the psychosocial impact of } \\
\text { rare diseases is adequate }\end{array}$ & $1.77(0,81)$ & $1.71(0.93)$ & 0.730 \\
\hline $\begin{array}{l}\text { I consider myself qualified to coordinate the health care of a patient } \\
\text { with a rare disease }\end{array}$ & $2.40(1.17)$ & $1.82(1.02)$ & 0.002 \\
\hline $\begin{array}{l}\text { I know the protocol of action that I must follow with a patient with a } \\
\text { rare disease }\end{array}$ & $2.19(1.12)$ & $1.58(0.83)$ & 0.002 \\
\hline $\begin{array}{l}\text { I feel qualified to give genetic counselling to my patients with rare } \\
\text { diseases }\end{array}$ & $2.02(1.01)$ & $1.41(0,74)$ & 0.001 \\
\hline $\begin{array}{l}\text { I know the existence of some of the registries of rare diseases existing } \\
\text { in our country }\end{array}$ & $2.33(1.29)$ & $2.10(1.26)$ & 0.305 \\
\hline $\begin{array}{l}\text { I have enough information about the operation of rare disease } \\
\text { registries }\end{array}$ & $1.79(0.99)$ & $1.58(0.84)$ & 0.154 \\
\hline I know what the Reference Units for rare diseases are & $2.40(1.22)$ & $1.97(1.11)$ & 0.029 \\
\hline $\begin{array}{l}\text { I know the role of these Reference Units in the monitoring of these } \\
\text { diseases }\end{array}$ & $2.38(1.29)$ & $1.87(1.07)$ & 0.009 \\
\hline $\begin{array}{l}\text { I know the existence of the State Reference Center for People with rare } \\
\text { diseases and their families }\end{array}$ & $2.09(1.23)$ & $1.87(1.14)$ & 0.272 \\
\hline I know how to refer patients to Reference Units & $2.47(1.32)$ & $1.53(0.77)$ & 0.001 \\
\hline $\begin{array}{l}\text { I know the functions performed by the State Reference Center for } \\
\text { People with Rare Diseases and their Families }\end{array}$ & $1.95(1.07)$ & $1.53(0.78)$ & 0.019 \\
\hline $\begin{array}{l}\text { I know the global / national organizations / associations working in the } \\
\text { field of rare disease }\end{array}$ & $2.26(1.09)$ & $1.58(0.85)$ & 0.001 \\
\hline Overall & $28.16(10.55)$ & $22.19(8.77)$ & 0.001 \\
\hline
\end{tabular}

*Significant difference $p<0.05$ 
Table 4 Overall score and medical specialty

\begin{tabular}{lll}
\hline Medical specialty & Mean & SD \\
\hline Gynecology & 18.7 & 7.5 \\
Hematology & 26.7 & 9.4 \\
Neurology & 28.5 & 6.9 \\
Oncology & 32.6 & 10.9 \\
Pediatric & 35.6 & 12.1 \\
Rural primary care & 21.6 & 8.7 \\
Urban primary care & 22.9 & 8.8 \\
\hline
\end{tabular}

*Differences $(p<0.05)$ between:

Oncology and pediatric vs urban primary care

Oncology and pediatric vs rural primary care

Oncology vs gynecologic

Pediatric vs gynecologic

social and health care or about where the referral centres may be indicated that there are still difficulties for an adequate management of RD, as described above. Avellaneda et al. [15] show that primary health care physicians have a low level of knowledge of RD, although a high interest, with emphasis on primary prevention, the importance of the family environment, genetic counselling and health education. Challenges for clinicians who care for affected individuals include gaining knowledge and experience in caring for such patients [24]. And important issue is being the contribution of the European Reference Networks (ERN), that bring all existing knowledge, experience and resources together, using three e-health and telemedicine tools $[25,26]$.

The lack of diagnostic and treatment guidelines and the difficulty in accessing genetic tests limit the possibilities of making an accurate and rapid diagnosis. Schieppati et al. [27] found that in $25 \%$ of the cases the diagnostic delay was from 5 to 30 years. In Spain the Spanish Undiagnosed Rare Diseases Program (SpainUDP) has been launched. SpainUDP offers a multidisciplinary approach to those patients who have long sought a diagnosis without any success [28].

About $46 \%$ of hospital doctors expressed that they have difficulty accessing treatments. Zurynsky's study [16] also found that about $40 \%$ of pediatricians had difficulty accessing treatments. It is unrealistic to consider that a doctor can know all the rare diseases described at this moment, but patients described the "diagnostic odyssey" to refer to that long process, often decades, that takes them from hospital to hospital, with misdiagnoses and inappropriate treatments [29]. Other countries have some experience with specific training in rare diseases. In France, all health professionals, medical doctors, midwives, nurses and paramedics attend a 2-h training session on rare diseases, which raises awareness and identifies sources of information on rare diseases for health professionals [20]. In Spain, it has been claimed for a long time that rare diseases are included in undergraduate Medicine and Nursing curricula and in postgraduate and continuing medical training [2].

The need to receive training on genetic counselling, diagnosis and treatment of RD, as well as information on web pages is clear, with scores very close to the maximum. A recent study by Vandeborne et al. [30] showed that when participants were asked if they needed rare disease information, $83 \%$ of the GPs, $95 \%$ of pediatricians, $97 \%$ of

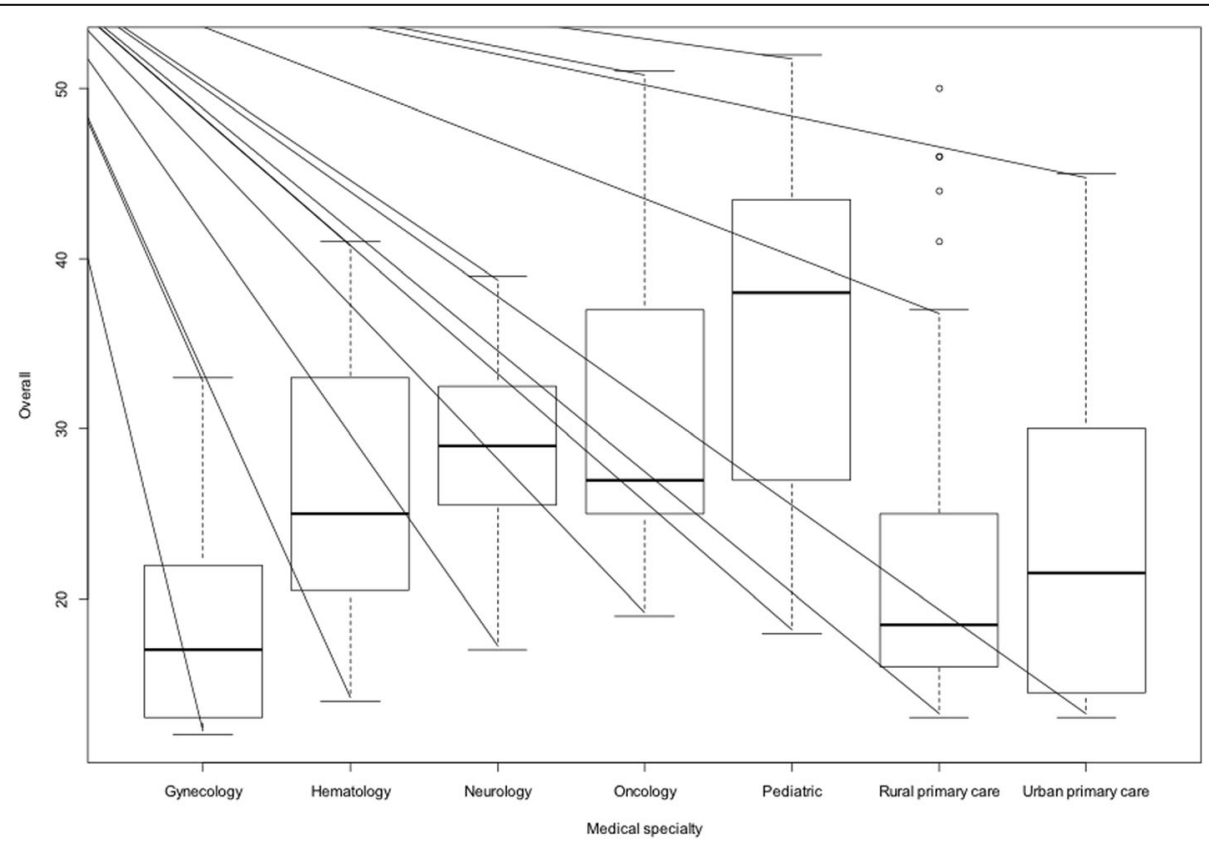

Fig. 1 Overall score and medical specialty 
Table 5 Multiple linear regression: factors related to overall score

\begin{tabular}{lll}
\hline Variable & Coefficient & $p$-value \\
\hline Men vs women & -0.293 & 0.817 \\
Years of practice & -0.009 & 0.897 \\
Hospital vs primary care & 5178 & $\mathbf{0 . 0 0 1}$ \\
Continuing vs No Continuing & 6738 & $\mathbf{0 . 0 0 1}$ \\
medical education & &
\end{tabular}

*Significant difference $p<0.05$

adult specialists and $100 \%$ of pediatric specialists indicated a need to have information on rare diseases.

There are some differences between primary care and hospital doctors. In general, the perceived training and knowledge of the resources available for the care or referral of patients is greater for hospital doctors. The reason, probably, is that the number of rare diseases faced by a hematologist or pediatrician is much smaller than those potentially seen by a General Practitioner. In a large survey directed at 837 patients with rare diseases, parents, and spouses and 531 health care professionals, it was also found that those respondents considered primary care physicians were much more likely to rate their level of knowledge as fair or poor (56.4\%) compared with respondents who were considered specialists (6.0\%) [10]. When physicians were specifically asked about their training, most (56.7\%) of the primary care respondents rated their training as neutral, ineffective, or very ineffective, compared to $40 \%$ of specialists [10]. Also, in Bulgaria, primary care physicians have a low level of general knowledge and awareness [31].

The number of physicians who had received continuing training in $\mathrm{RD}$ is less than $40 \%$, although this figure is double of that reported by Avellaneda et al. [15]. Although this percentage is not very high, the study has also shown that doctors who had received continuing education courses felt better prepared and more knowledgeable to care for the sick. This result shows the need to implement ongoing training programs to improve the degree of clinical knowledge and diagnosis related to RD, as well as to publicize the existence of socio-health-type resources and patient associations among physicians. In 2006, primary care physicians in Spain created a working group on rare diseases to improve care for these patients [32].

There are some limitations to this study. Firstly, our hospital is a medium-sized centre (630 beds) and it is not a reference hospital for the diagnosis or treatment of rare diseases. Second, the response rate was $64.0 \%$. No significant differences between respondents and nonresponders were found in clinicians age, years of professional practice, sex, or work environment. We assume, therefore, that the non-response is random and not introduce a qualitative bias in the results.

\section{Conclusion}

In conclusion, the study supports other investigations that have shown that clinicians lack easy access to educational opportunities and information resources regarding rare diseases. It is imperative that the public health system includes ongoing training on rare diseases in programs to improve the training of physicians in both primary care and specialized care.

\section{Supplementary information}

Supplementary information accompanies this paper at https://doi.org/10. 1186/s13023-019-1285-0.

Additional file 1. Questionnaire

\section{Abbreviations}

CME: Continuing medical education; ERN: European Reference Network; EU: European Union; FEDER: Fondo Europeo de Desarrollo Regional; GP: General Practitioner; RD: Rare disease; SD: Standar Desviation; Spain UDP: Spanish Undiagnosed Rare Diseases Program; UK: United Kingdom; USA: United States of America

\section{Acknowledgements}

The authors are pleased to acknowledge all physicians who participated by completing the questionnaire.

\section{Authors' contributions}

ERG, EDG, MGE, MEMS, JLRT and MJGG participated in the original design of the study. EDG, MGE, JLRT supervised the collection of data. ERG and MJGG performed the statistical analyses. All authors had full access to all of the study data, assisted in the interpretation of the data, and have seen and approved the final version of the report.

\section{Funding}

This project has been partially supported by "Fondo Europeo de Desarrollo Regional (FEDER): La Rioja crece con Europa".

\section{Availability of data and materials}

See additional files.

Ethics approval and consent to participate

This study, with protocol number 259, was approved by Research Ethics Committee of La Rioja, Spain (CEICLAR) on the 18th of August 2017.

Consent for publication

Not applicable.

\section{Competing interests}

All authors declare that they have no competing interests. All authors read and approved the final manuscript.

\section{Author details}

${ }^{1}$ Department of Epidemiology, La Rioja Government, La Rioja, Spain. ${ }^{2}$ Rioja Health Foundation, La Rioja, Spain. ${ }^{3}$ Neurology Department, San Pedro Hospital, La Rioja, Spain. ${ }^{4}$ Primary Care Service, La Rioja, Spain. ${ }^{5}$ Teaching Department of Specialized Health Training, La Rioja, Spain.

Received: 31 July 2019 Accepted: 20 December 2019

Published online: 17 January 2020

\section{References}

1. Richter T, Nestler-Parr S, Babela R, et al. Rare disease terminology and definitions-a systematic global review: report of the ISPOR rare disease special interest group. Value Health. 2015;18:906-14.

2. Palau F. Rare diseases, an emergent paradigm in the medicine of the XXI century. Med Clin (Barc). 2010;134(4):161-8. https://doi.org/10.1016/j.medcli. 2009.06.038. 
3. World Health Organization. Coming Together to Combat Rare Diseases. Bull World Health Organ. 2012;90:406-7. MDPI AG. https://doi.org/10.1016/j. semerg.2012.02.011.

4. Garau R. The medical experience of a patient with a rare disease and her family. Orphanet J Rare Dis. 2016;11(1). https://doi.org/10.1186/ s13023-016-0401-7.

5. Alonso V, Abaitua I, Zurriaga Ó, et al. National rare diseases registry in Spain: pilot study of the Spanish rare diseases registries research network (SpainRDR). Orphanet J Rare Dis. 2014;9(Suppl 1):P5. https://doi.org/10.1186/ 1750-1172-9-s1-p5.

6. Vandeborne L, Overbeeke E, Dooms M, et al. Information needs of physicians regarding the diagnosis of rare diseases: a questionnaire-based study in Belgium. Orphanet J Rare Dis. 2019;14:99. https://doi.org/10.1186/ s13023-019-1075-8.

7. Avellaneda A, Layola M, Izquierdo M, Guilera M, Badia X, Ramón JR. Sociosanitary impact on patients with rare diseases (ERES study). Med Clin (Barc). 2007;129(17):646-51

8. Huete A, Díaz E. Estudio sobre situación de necesidades Sociosanitarias de las personas con Enfermedades Raras en España. Estudio ENSERio. Available in: enfermedades-raras.org/images/stories/documentos/Estudio_ENSERio.pdf

9. Kopeć G, Podolec P. Establishing a curriculum on rare diseases for medical students. J Rare Cardiovasc Dis. 2016;2(3). https://doi.org/10.20418/jrcd. vol2no3.194.

10. Engel PA, Bagal S, Broback MAS, Boice N. Physician and patient perceptions regarding physician training in rare diseases: the need for stronger educational initiatives for physicians. J Rare Dis. 2013;1:2.

11. Budych K, Helms TM, Schultz C. How do patients with rare diseases experience the medical encounter? Exploring role behavior and its impact on patient-physician interaction. Health Policy (New York). 2012;105(2-3): 154-64. https://doi.org/10.1016/.healthpol.2012.02.018.

12. Eucerd recommendations on rare disease european reference networks ( $r d$ erns). Available in http://www.eucerd.eu/?post type $=$ document $\& p=2207$

13. Ministry of Health from Spain. Estrategia En Enfermedades Raras De Sistema Nacional de Salud Sanidad: Ministerio de Sanidad, Servicios Sociales e lgualdad; 2013. Available in: https://www.mscbs.gob.es/organizacion/sns/ planCalidadSNS/pdf/Estrategia_Enfermedades_Raras_SNS_2014.pdf

14. Ramalle-Gómara E, Ruiz E, Quiñones C, Andrés S, Iruzubieta J, Gil-De-Gómez J. General knowledge and opinion of future health care and non-health care professionals on rare diseases. J Eval Clin Pract. 2015;21(2):198-201. https://doi.org/10.1111/jep.12281.

15. Avellaneda Fernández A, Pérez Martín A, Pombo Allés G, Gutiérrez Delgado E, lzquierdo MM. Percepción de las enfermedades raras por el médico de atención primaria. Semergen. 2012;38(7):421-31. https://doi.org/10.1016/j. semerg.2012.02.011.

16. Zurynski Y, Gonzalez A, Deverell M, et al. Rare disease: a national survey of paediatricians' experiences and needs. BMJ Paediatr Open. 2017;1 (1): e000172. https://doi.org/10.1136/bmjpo-2017-000172.

17. Esteban G, Ruano M, de los Santos JM G, Motero I. Conocimientos Médicos Sobre Enfermedades Raras Por Parte de Los Profesionales de La Salud. Salud(i)Ciencia. 2015;21:604-9.

18. Metcalfe S, Hurworth R, Newstead J, Robins R. Needs assessment study of genetics education for general practitioners in Australia. Genet Med. 2002 4(2):71-7. https://doi.org/10.1097/00125817-200203000-00004

19. Danese E, Lippi G. Rare diseases: the paradox of an emerging challenge. Ann Transl Med. 2018:6(17):329. https://doi.org/10.21037/atm.2018.09.04

20. Elliott E, Nicoll A, Lynn R, Marchessault V, Hirasing R, Ridley G. Rare disease surveillance: an international perspective. Paediatr Child Health. 2001;6:251-60.

21. Jo A, Larson S, Carek P, Peabody MR, Peterson LE, Mainous AG. Prevalence and practice for rare diseases in primary care: A national cross-sectional study in the USA. BMJ Open. 2019;9(4). https://doi.org/10.1136/bmjopen2018-027248.

22. Mendelian, n.d. The role of the GP in rare disease diagnosis and care. Available in https://www.mendelian.co/the-role-of-gp-in-rare-diseasediagnosis-and-care

23. Pai M, Yeung CHT, Akl EA, et al. Strategies for eliciting and synthesizing evidence for quidelines in rare diseases. BMC Med Res Methodol. 2019:19(1). https://doi.org/10.1186/s12874-019-0713-0

24. Stoller JK. The challenge of rare diseases. Chest. 2018;153(6):1309-14. https://doi.org/10.1016/j.chest.2017.12.018.

25. Héon-Klin V. European reference networks for rare diseases: what is the conceptual framework? Orphanet J Rare Dis. 2017;12(1):137.
26. Gulhan I. A unique e-health and telemedicine implementation: European reference networks for rare diseases. J Public Health. 2019. https://doi.org/ 10.1007/s10389-019-01052-w.

27. Schieppati A, Henter J-I, Daina E, Aperia A. Why rare diseases are an important medical and social issue. Lancet. 2008;371(9629):2039-41. https:// doi.org/10.1016/S0140-6736(08)60872-7.

28. López-Martín E, Martínez-Delgado B, Bermejo-Sánchez E, Alonso J. SpainUDP: The Spanish undiagnosed rare diseases program. Int J Environ Res Public Health. 2018;15(8). https://doi.org/10.3390/ijerph15081746.

29. Evans WR, Rafi I. Rare diseases in general practice: recognising the zebras among the horses. Br J Gen Pract. 2016;66(652):550-1. https://doi.org/10. 3399/bjgp16×687625.

30. Vandeborne L, Van Overbeeke E, Dooms M, De Beleyr B, Huys I. Information needs of physicians regarding the diagnosis of rare diseases: a questionnaire-based study in Belgium; 2019. https://doi.org/10.1186/s13023019-1075-8

31. Miteva T, Jordanova R, Iskrov G, Stefanov R. General knowledge and awareness on rare diseases among general practitioners in Bulgaria. Georgian Med News. 2011;193:16-9 http://www.ncbi.nlm.nih.gov/ pubmed/21617267.

32. García-Ribes M, Ejarque I, Arenas E, Martín V. Nuevos retos: El médico de familia ante las «enfermedades raras». Aten Primaria. 2006;37(7):369-70. https://doi.org/10.1157/13087370

\section{Publisher's Note}

Springer Nature remains neutral with regard to jurisdictional claims in published maps and institutional affiliations.
Ready to submit your research? Choose BMC and benefit from:

- fast, convenient online submission

- thorough peer review by experienced researchers in your field

- rapid publication on acceptance

- support for research data, including large and complex data types

- gold Open Access which fosters wider collaboration and increased citations

- maximum visibility for your research: over $100 \mathrm{M}$ website views per year

At $\mathrm{BMC}$, research is always in progress.

Learn more biomedcentral.com/submissions 